\title{
Obesity in pregnancy: maternal and perinatal outcome
}

Prameela H. J.*, Madhuri S.

Department of Obstetrics and Gynecology, Mysore Medical College and Research Institute, Mysore, Karnataka, India

Received: 20 October 2016

Accepted: 15 November 2016

\section{*Correspondence:}

Dr. Prameela H. J.,

E-mail: hjprameela@gmail.com

Copyright: (c) the author(s), publisher and licensee Medip Academy. This is an open-access article distributed under the terms of the Creative Commons Attribution Non-Commercial License, which permits unrestricted non-commercial use, distribution, and reproduction in any medium, provided the original work is properly cited.

\begin{abstract}
Background: Obesity, the silent epidemic worldwide has reached a stage where approximately 2.3 billion adults will be overweight and more than 700 million adults will be obese by 2015 , as projected by WHO. The objective of this study was to find out the incidence of the pregnancy complications due to maternal obesity and to assess the neonatal outcome.

Methods: Retrospective study conducted in Cheluvamba Hospital, Mysore from September 2014 to September 2015. Subjects were categorized into 3 classes based on the BMI. Class 1:30-34.9 kg/m², class 11:35-39.9 kg/m², Class 111 : $>40 \mathrm{~kg} / \mathrm{m}^{2}$. The maternal and perinatal outcome of the subjects evaluated in relation to body mass index.

Results: A total of 56 women were included in the study, with 37 belonging to class I, 13 women class II, 6 women class III. Class III women were significantly more likely to have pre-eclampsia $(83.3 \%, 69.2 \%, 27 \%)$ and post term pregnancy $(50 \%, 38 \%, 16.2 \%)$ than class II and class I. The incidence of GDM $(7.6 \%, 5.4 \%)$ and IUGR $(7.6 \%, 2.7 \%)$ are more in class II compared to class I. Instrumental deliveries $(10 \%, 28.5 \%)$ and LSCS $(45.9 \%, 46.1 \%, 66.6 \%)$ rates increased as the BMI increased from class I to class III. Postpartum complications like PPH $(5.4 \%, 7.6 \%, 33.3 \%)$ and wound gapping $(7.6 \%, 16.6 \%)$ were on rise with increased BMI. Class III women were more likely to have macrosomic babies than class II and class III $(33.3 \%, 15.3 \%, 18.9 \%)$.

Conclusions: As the BMI increases pregnancy is more likely to get complicated. Interventions directed towards weight loss and prevention of excessive weight gain must begin in the pre-conception period. Obstetrical care providers must counsel their obese patients regarding the risks and complications conferred by obesity and the importance of weight loss.
\end{abstract}

Keywords: Maternal outcome, Obesity, Perinatal Outcome

\section{INTRODUCTION}

Obesity, the silent epidemic worldwide has reached a stage where approximately 2.3 billion adults will be overweight and more than 700 million adults will be obese by 2015 , as projected by WHO. ${ }^{1}$ National Family Health Surveys in India indicated an increase in obesity from $10.6 \%$ in $1998-1999$ to $14.8 \%$ in $2005-06$. Obesity is increasing, both in the general population and in women of reproductive age. Obesity in pregnant women increases the risks of maternal and perinatal complications. WHO has defined the criteria of overweight as BMI $>25 \mathrm{~kg} / \mathrm{m}^{2}$ and that for obesity as BMI $>30 \mathrm{~kg} / \mathrm{m}^{2}{ }^{2}$ The increasing prevalence of obesity worldwide has prompted the WHO to designate obesity as one of the most important public health threats in the world. The four states in South India also being the predominantly rice eating population have a high incidence in obesity among women3. Several studies in India have reiterated the fact that vaginal delivery, postpartum infection, post-delivery deep vein thrombosis obesity in pregnancy puts the mother and the fetus at the risk of several complications such as gestational diabetes mellitus, pregnancy induced hypertension, preeclampsia, 
preterm labour, dysfunctional labour, caesarean section, instrumental delivery. Neonates of obese women were mostly large for gestational age, macrosomic and they had high incidences of birth injuries, shoulder dystocia, premature deliveries, late fetal deaths and congenital malformations particularly spina bifida, cleft lip, cleft palate and heart defect. ${ }^{4}$

This purpose of this study is to find out the incidence of the pregnancy complications due to maternal obesity and to assess the neonatal outcome and obstetric outcome and to educate treating clinicians regarding the importance of pre-conceptional counseling regarding obesity and related issues. The results of this study will enable to highlight a problem that is a modifiable risk factor for several conditions in pregnancy and also a long term risk factor for cardiovascular diseases and for diabetes mellitus.

\section{METHODS}

This is a retrospective study conducted in Cheluvamba Hospital Mysore from September 2014 to September 2015.Samples were selected randomly and the information needed for the study was taken from the medical records. Subjects were categorized into 3 classes based on the BMI.

- Class I: $30-34.9 \mathrm{~kg} / \mathrm{m}^{2}$

- Class II: $35-39.9 \mathrm{~kg} / \mathrm{m}^{2}$

- Class III: $>40 \mathrm{~kg} / \mathrm{m}^{2}$
The maternal and perinatal outcome of the subjects evaluated in relation to body mass index.

\section{RESULTS}

A total of 56 women were included in the study fulfilling the inclusion criteria with BMI $>30 \mathrm{~kg} / \mathrm{m}^{2}$. They were further divided into 3 classes (Figure 1).

- Class I: BMI $30-34.9 \mathrm{~kg} / \mathrm{m}^{2}$ included 37 women

- Class II: BMI $35-39.9 \mathrm{~kg} / \mathrm{m}^{2}$ included 13 women

- Class III: BMI $>40 \mathrm{~kg} / \mathrm{m}^{2}$ included 6 women.

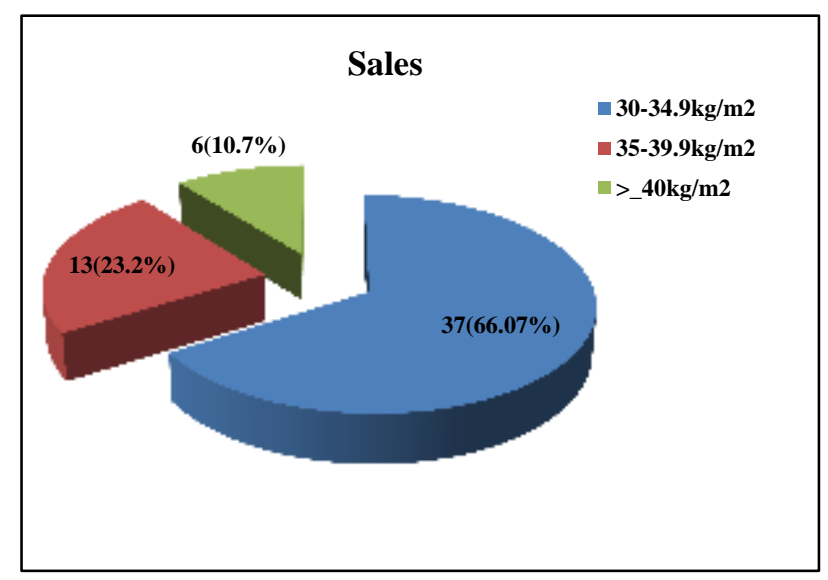

Figure 1: Distribution of study subjects.

Table 1: Antepartum complications in relation to BMI.

\begin{tabular}{|lllll|}
\hline GDM & Class I $(\mathbf{n}=37)$ & Class II $(\mathbf{n}=13)$ & Class III $(\mathbf{n}=\mathbf{6})$ & Total $(\mathbf{n}=56)$ \\
\hline Pre eclampsia & $2(5.4 \%)$ & $1(7.6 \%)$ & - & $5(53 \%)$ \\
\hline Post term pregnancy & $10(27 \%)$ & $9(69.2 \%)$ & $3(50 \%)$ & $24(42.8 \%)$ \\
\hline Oligohydromnias & $6(16.2 \%)$ & $5(38 \%)$ & - & $14(25 \%)$ \\
\hline Polyhydromnias & $3(8.1 \%)$ & $3(23 \%)$ & - & $1(10.7 \%)$ \\
\hline IUGR & $1(2.7 \%)$ & - & - & $2(3.5 \%)$ \\
\hline Preterm labor & $1(2.7 \%)$ & $1(7.6 \%)$ & & $2(3.5 \%)$ \\
\hline
\end{tabular}

Table 2: Mode of delivery in relation to BMI.

\begin{tabular}{|lllll|}
\hline & Class I $(\mathbf{n}=\mathbf{3 7})$ & Class II $(\mathbf{n}=\mathbf{1 3})$ & Class III $(\mathbf{n}=\mathbf{6})$ & Total $(\mathbf{n}=56)$ \\
\hline Vaginal & $20(54 \%)$ & $7(53.8 \%)$ & $2(33.3 \%)$ & $29(51.7 \%)$ \\
\hline Spontaneous delivery & $13(65 \%)$ & $3(42.8 \%)$ & $1(50 \%)$ & $17(58.6 \%)$ \\
\hline Induced & $5(25 \%)$ & $2(28.5 \%)$ & $1(50 \%)$ & $8(27.5 \%)$ \\
\hline Instrumental & $2(10 \%)$ & $2(28.5 \%)$ & - & $4(13.7 \%)$ \\
\hline LSCS & $17(45.9 \%)$ & $6(46.1 \%)$ & $4(66.6 \%)$ & $27(48.2 \%)$ \\
\hline
\end{tabular}

\section{Ante partum complications and its relation with BMI}

Out of 56 women 24 women had preeclampsia, of which 10 women were between BMI $30-34.9 \mathrm{~kg} / \mathrm{m}^{2}$, 9 were between BMI 35-39.9 $\mathrm{kg} / \mathrm{m}^{2}$, 5 were with BMI >40 $\mathrm{kg} / \mathrm{m}^{2}$. 3 women had gestational diabetes mellitus. 14 women were post term, of which 6 were between BMI 30-34.9 kg/m 2 , 5 were between BMI 35-39.9 kg/m², 3 women with BMI>40 $\mathrm{kg} / \mathrm{m}^{2} .2$ women had IUGR. 2 
women had preterm labor. Oligohydramnios were seen in 6 women, of which 3 were between BMI $30-34.9 \mathrm{~kg} / \mathrm{m}^{2}$ and 3 were between $35-39.9 \mathrm{~kg} / \mathrm{m}^{2}$. Polyhydramnios were seen in one woman.

\section{Mode of delivery}

Of the total 56 women, 29 women delivered vaginally and 27 by LSCS. Of the 29 women delivered vaginally 17 were spontaneous, 8 were induced and 4 instrumental
Of the total 56 women, 29 women delivered vaginally and 27 by LSCS. Of the 29 women delivered vaginally 17 were spontaneous, 8 were induced and 4 instrumental deliveries. Majority of the indications for LSCS is failed induction $(n=10)$, followed by fetal distress $(n=6)$.

deliveries. Majority of the indications for LSCS is failed induction $(n=10)$, followed by fetal distress $(n=6)$.

\section{Indication for LSCS}

Table 3: Indication of LSCS in relation to BMI.

\begin{tabular}{|lllll|}
\hline Indications & Class I $(\mathbf{n}=\mathbf{1 7})$ & Class II $(\mathbf{n}=\mathbf{6})$ & Class III $(\mathbf{n}=4)$ & Total $(\mathbf{n}=28)$ \\
\hline Failed induction & $5(29.4 \%)$ & $2(33.3 \%)$ & $3(75 \%)$ & $10(35.7 \%)$ \\
\hline Fetal distress & $3(17.6 \%)$ & $3(50 \%)$ & - & $6(21.4 \%)$ \\
\hline CPD & $3(17.6 \%)$ & - & - & $3(10.7 \%)$ \\
\hline Deep transverse arrest & $3(16.6 \%)$ & - & - & $3(10.7 \%)$ \\
\hline $\begin{array}{l}\text { Secondary arrest in } \\
\text { descent and dilatation }\end{array}$ & $2(11.7 \%)$ & - & - & $2(7.1 \%)$ \\
\hline Severe preeclampsia & $1(5.8 \%)$ & $1(16.6 \%)$ & $-7 \%)$ \\
\hline
\end{tabular}

Table 4: Intrapartum and postpartum complications.

\begin{tabular}{|lllll|}
\hline COMIPLICATION & Class I $(n=37)$ & Class II $(n=13)$ & Class III $(n=6)$ & Total $(\mathbf{n}=56)$ \\
\hline PPH & $2(5.4 \%)$ & $1(7.6 \%)$ & $2(33.3 \%)$ & $5(8.9 \%)$ \\
\hline Cervical/vaginal tears & $2(5.4 \%)$ & - & - & $2(3.5 \%)$ \\
\hline Wound gapping & & $1(7.6 \%)$ & $1(16.6 \%)$ & $2(3.5 \%)$ \\
\hline
\end{tabular}

Table 5: Perinatal outcome.

\begin{tabular}{|lllll|}
\hline & Class I $(\mathbf{n}=\mathbf{3 7})$ & Class II $(\mathbf{n}=\mathbf{1 3})$ & Class III $(\mathbf{n}-\mathbf{6})$ & Total $(56)$ \\
\hline NICU & $6(16.2 \%)$ & $7(53.8 \%)$ & - & $13(23.2 \%)$ \\
\hline Weight $>3.5 \mathrm{~kg}$ & $7(18.9 \%)$ & $2(15.3 \%)$ & $2(33.3 \%)$ & $11(19.6 \%)$ \\
\hline Weight $<3.5 \mathrm{~kg}$ & $30(81.08 \%)$ & $11(84.6 \%)$ & $4(66.6 \%)$ & $45(80.3 \%)$ \\
\hline
\end{tabular}

\section{Intra-partum and post-partum complications}

Of the 56 women post-partum hemorrhage was encountered in 5 women $(8.9 \%)$, of which 2 women delivered vaginally and 3 by cesarean. Two women had cervical tear. 2 women had wound gaping postoperatively and one women developed peripartum cardiomyopathy.

\section{Perinatal complications}

Out of 56 babies delivered 13 needed NICU admissions due to low APGAR scores. Macrosomia was seen in 11 babies.

\section{DISCUSSION}

A number of systems have been used to define and classify obesity. The body mass index (BMI), also known as the Quetelet index, is currently most often used. The
BMI is calculated as weight in kilograms divided by the square of the height in meters $\left(\mathrm{kg} / \mathrm{m}^{2}\right){ }^{4}$

Antenatal complications: In our study as the BMI increased the incidence of pre-eclampsia increased from $27 \%$ in those with BMI $30-35 \mathrm{~kg} / \mathrm{m}^{2}$ to $69.2 \%$ in those with BMI $35-39.9 \mathrm{~kg} / \mathrm{m}^{2}$ and $83.3 \%$ in those with BMI $>40 \mathrm{~kg} / \mathrm{m}^{2}$ The overall incidence of pre-eclampsia in obese women is $42.8 \%$ which is consistent with the study conducted by Dasagupta et al were the incidence of hypertensive disorders is $38 \%{ }^{1}$ In a study conducted by Kabiru et al showed the incidence of hypertensive disorders in obese women as $35.4 \%{ }^{5}$

The increase in the risk of GDM increased with the increase in BMI from $5.4 \%$ in class I obese women to $7.6 \%$ in class II obese women. The overall incidence of GDM is $5.3 \%$. In a study of 16102 women, the incidence of GDM was $2.3 \%$ in the control group and increased to 
$6.3 \%$ in the obese group (OR 2.6) and 9.5\% in the morbidly obese group (OR 4.0). ${ }^{6}$ Therefore, diabetes is associated with increasing overweight and obesity.

Post term pregnancy was seen in $25 \%$ women and the percentage women with post term pregnancy increased as BMI increased. Obese women are more likely to go for posterm pregnancy and induction of labor.

Obese women are more prone for delivery by cesarean section. In our study the rate of cesarean increased with BMI. Lynch et al. studied over 5000 subjects in a retrospective cohort study, and showed that delivery by caesarean section was two- to threefold more likely in obese women. The same study also found that there was a progressive reduction in the successful vaginal delivery rate with increasing BMI, consistent with findings in our study. ${ }^{7}$

Post-partum hemorrhage and wound infections were significantly raised from obese women $(5.4 \%, 0 \%)$ to morbidly obese women $(33.3 \%, 16.6 \%)$. Alanis et al had demonstrated higher risks of post caesarean wound gape, discharge and seroma formation among the morbidly obese.

\section{CONCLUSION}

Obesity causes significant complications for the mother and fetus. Interventions directed towards weight loss and prevention of excessive weight gain must begin in the pre-conception period. Obstetrical care providers must counsel their obese patients regarding the risks and complications conferred by obesity and the importance of weight loss. Maternal and fetal surveillance may need to be heightened during pregnancy; a multidisciplinary approach is useful. Women need to be informed about both maternal and fetal complications and about the measures that are necessary to optimize outcome, but the most important measure is to address the issue of weight prior to pregnancy. Obesity in pregnancy is a major predictor of obesity later in life, which is commonly associated with the development of chronic hypertension, dyslipidaemia and T2DM.Therefore, from a public health perspective, obesity represents an important modifiable risk factor for adverse pregnancy outcome..

Funding: No funding sources

Conflict of interest: None declared

Ethical approval: The study was approved by the Institutional Ethics Committee

\section{REFERENCES}

1. Dasgupta A, Harichandrakumar KT, Syed Habeebullah S. Pregnancy outcome among obese Indians - a prospective cohort study in a tertiary care centre in South India. Int J Sci Stud. 2014;2(2):13-8.

2. Flier JS, Maratos-Flier E. Biology of obesity. In: Fauci, Braunwald, Kasper, Hauser, Longo, Jameson, Loscalzo. Harrison's Principles of Internal Medicine. 17th edition. New York: McGraw-Hill; 2008:463.

3. Arnold F, Parasuraman S, Arokiasamy P, Kothari M. National family health survey (NFHS-3) 2005-06. Available at http://www.popline.org/node/209673.

4. Cunningham FG, Lenovo KJ, Bloom SL, Hauth JC, Gilstrap L, Wenstrom KD. Obesity. Williams Obstetrics. 24th edition. New York: McGraw-Hill Companies; 2005:946.

5. Kabiru W, Raynor BD. Obstetric outcomes associated with increase in BMI category during pregnancy. Am J Obstet Gynecol. 2004;191:928-32.

6. Yu C, Teoh T, Robinson S. Obesity in pregnancy. BJOG. 2006;113:1117-25.

7. Lynch CM, Sexton DJ, Hession M, Morrison JJ. Obesity and mode of delivery in primigravid and multigravid women. Amer J Perinatol. 2008;25(3):163-7.

Cite this article as: Prameela HJ, Madhuri S. Obesity in pregnancy: maternal and perinatal outcome. Int J Reprod Contracept Obstet Gynecol $2017 ; 6: 141-4$. 